\title{
A Simple and Unique Habit which can Prevent Many Diseases Throughout Life
}

\author{
SS Nair* \\ Retired Director (Evaluation), Ministry of Health and Family Welfare, India \\ *Corresponding Author: SS Nair, Retired Director (Evaluation), Ministry of Health \\ and Family Welfare, India.
}

Revered Buddha who got enlightenment says: "Every human being is the author of his own health and disease".

One way to take charge of health is to prevent diseases which are common. There are many diseases that are caused by infecting organisms which enter body through nose or mouth. Examples are: covid-19, influenza and other viral fevers, common cold, cough, chickenpox, measles, rubella, whooping cough, diphtheria, polio, tuberculosis, etc.

It is generally believed that these diseases are spread because infecting organisms are thrown out through nose when an infected person sneezes. Do you believe this? If so, you have to believe that these infecting organisms can be thrown out by nose blowing also. In fact, nose blowing will act on these tiny organisms like "cyclone storm" and throw these out.

Nose blowing results in exhalation of air from lungs to windpipe, throat and nose. Infecting organisms in all these parts (and maybe even upper part of lungs) will be thrown out by nose blowing. Therefore, one sure method to prevent any of these diseases is to blow each nose thrice so that infecting organisms, whenever present, will be thrown out. The two extra nose blowings, one after the other, are intended for additional safety. This will also counteract against any inability to blow nose properly due to any problem and ensure that even slow nose blowing will be effective.

As abundant extra precautions, blow each nose thrice, 3 to 6 times a day, depending upon time spent outside house and intensity of infection in the area visited.

There are 2 additional benefits - over a period of time, this repeated nose blowing habit will (a) strengthen lungs and (b) strengthen nose to overcome any problem in blowing nose.
Received: February 27, 2021

Published: April 06, 2021

(C) All rights are reserved by SS Nair.
It is encouraging that blowing both noses 3 times at a time takes less than 10 seconds and even the maximum of six times a day needs less than one minute only. It may be reemphasised that this easy method takes many extra precautions to ensure that infecting organisms do not remain in body and cause harm.

To ensure that nose blowing becomes a regular habit, it is better to connect this with other habits. For example, if you are blowing nose thrice a day this can be regularly done along with the hygienic practice of washing hand before breakfast, lunch and dinner.

This regular habit has the unique distinction that it can singly give protection against many diseases throughout life. Therefore, it is important to start this habit from childhood. This ability to prevent many diseases anytime in life will help to get rid of fear and anxiety about these diseases. A valuable benefit from these preventions is saving of money and time for repeatedly visiting doctors, hospitals and medicine shops.

Corona pandemic and tuberculosis are of special interest because these cause millions of cases and thousands of deaths every year and attempts at eradication of these diseases have failed. Corona viruses and tubercle bacilli will be thrown out by nose blowing in the same way as these are being thrown out when an infected person sneezes. Therefore, both can be eradicated if all people practice this daily habit regularly - a praiseworthy achievement by people themselves. Because most children are infected by tubercle bacilli before age 20 , children should develop nose blowing habit as early as possible.

Obviously, this single but effective preventive method against many diseases is praiseworthy and highly deserve daily practice. Other advantages are: (a) it does not do any harm, (b) does not need money for equipments or medicines or payment for service, 
(c) needs only less than 10 seconds each time, (d) this can be easily practised by anyone without approval or help, (e) ability to prevent many diseases anytime in life will help to get rid of fear and anxiety about these diseases, (f) can repeatedly save lot of money and time for visiting doctors, hospitals and medicine shops, (g) mutation of virus will not affect its effectiveness and (h) there is all to gain and nothing to lose by this habit.

These facts also confirm that this simple and unique preventive method which singly prevents many diseases throughout life is preferable to vaccination in many aspects and does not cost money unlike costly vaccination.

All that is needed is determination of everyone to spare less than a maximum of one minute a day and regularly practise this easy and harmless nose blowing method.

You can be always prepared to throw out all infecting organisms soon after these enter body through nose or mouth, only if you refuse to be callous and make nose blowing a regular habit. If everyone acts like this with determination, we can rejoice that we have succeeded in preventing many diseases mentioned earlier, particularly covid-19 and tuberculosis which caused immense harm and could not be eradicated. People can be proud of all these praiseworthy achievements without any help.

It was suggested in page 1 that nose blowing has to be done 3 to 6 times a day, depending upon time spent outside house and intensity of infection in area visited. This is because, to get full protection, the interval between nose blowings has to be shorter than the time these organisms take to go from nose to the target where they multiply and do harm.

One problem faced is that how much time these infecting organisms take to go from nose to their target and whether this time will differ for different organisms are not known. These have to be ascertained through research. Then, the method can be simplified and restricted to one or two nose blowing per day. But, how long it will take to complete such studies and whether these will give useful results are open to question.

Because of the strong possibility of having large number of cases and deaths under the corona pandemic, it is not desirable to wait for results of these studies, particularly so because nose blowing can be done without any harm. Moreover, it is likely that these tiny organisms without wings will take long time to climb up and reach their target because these have to move against regular up and down movement of air due to breathing. Therefore, even long intervals between nose blowings are sufficient to prevent these organisms from reaching their target. Moreover, the additional precautions suggested are likely to ensure safety.

A serious problem which stood in the way of many improvements in health is that millions of people ignored health warnings and suggestions (e.g. against smoking, drinking and drugs and regarding wearing masks and keeping social distance etc.) despite extensive propaganda. Some reasons may be "it will not happen to me" arrogance or carelessness to act in time or limitation in rational thinking. It is essential to carry out psychological studies to ascertain reasons for this serious blocking problem and how to overcome these.

Meanwhile, the damaging corona pandemic situation demands that governments and people should take immediate action to educate people not to create these blocks in attending to health warnings and suggestions. Every individual should (1) practise nose blowing habit regularly, (2) send urgent explanatory messages about nose blowing habit to all contacts and (3) explain in detail the purpose and effectiveness of nose blowing habit to all persons in middle and poor classes with whom they come into contact because they live in crowded areas and need this preventive habit most.

An encouraging possibility is that if fairly large number of people practise nose blowing habit regularly, number of new cases of covid-19 will come down fast. This will give an assurance that the intervals between nose blowings which were used daily are proper and effective and no further studies need be carried out urgently to ascertain the proper intervals to be used as suggested earlier.

\section{Assets from publication with us}

- Prompt Acknowledgement after receiving the article

- Thorough Double blinded peer review

- Rapid Publication

- Issue of Publication Certificate

- High visibility of your Published work

Website: www.actascientific.com/

Submit Article: www.actascientific.com/submission.php

Email us: editor@actascientific.com

Contact us: +919182824667 